\title{
Synergy and Correlation Optimization Analysis of Innovation System and Institutional Governance System from the Perspective of Cluster Ecosystem
}

\author{
Jian Sun $\mathbb{D}^{1,2}$ Hua Zou ${ }^{10},{ }^{1}$ and Deyu He ${ }^{1}$ \\ ${ }^{1}$ School of Management, Shenyang University of Technology, Shenyang 110870, China \\ ${ }^{2}$ School of Business Administration, Shenyang Polytechnic College, Shenyang 110000, China \\ Correspondence should be addressed to Hua Zou; suo-2001@163.com
}

Received 14 July 2021; Revised 28 October 2021; Accepted 17 November 2021; Published 3 December 2021

Academic Editor: Bo Zeng

Copyright (c) 2021 Jian Sun et al. This is an open access article distributed under the Creative Commons Attribution License, which permits unrestricted use, distribution, and reproduction in any medium, provided the original work is properly cited.

\begin{abstract}
Innovation and institutional governance are the key enabling factors of cluster ecosystem development. Its synergistic effects play an important role in enhancing ecosystem competitiveness. In this paper, pseudocode language is applied to cluster ecosystem cooperative model reasoning. The coordination and optimization of the innovation system and institutional governance system were studied in a biomedical cluster. Besides, Pearson algorithm was used to test the correlation degree of elements in three Chinese biomedical clusters. The results show that, in Zhangjiang and Nanchang biomedical clusters, the synergistic correlation coefficient between the innovation system and the institutional governance system fluctuates around 0.8. However, in Tonghua biomedical cluster, the synergy correlation coefficient fluctuated around -0.2. The fluctuation range between the two clusters was large. After adjusting the range of order parameters, the rank of synergy trend was Zhangjiang $>$ Nanchang $>$ Tonghua. Finally, further analysis shows that Zhangiiang and Nanchang biomedical clusters can achieve the optimal synergy state by adjusting innovation and institutional governance, but Tonghua cannot. Therefore, the collaboration between the innovation system and institutional governance system provides some reference for the high-quality development of the cluster ecosystem.
\end{abstract}

\section{Introduction}

Cluster gathering has become a typical form of rapid development in China under the influence of the socialist system with Chinese characteristics. The industrial cluster has become an important tool to enhance China's global competitiveness. The formation and growth of clusters have obvious ecological characteristics [1]. As a compound system, a cluster ecosystem is an effective way to improve regional economic competitiveness [2]. In China, many industries are currently overcapacity [3]. This problem directly affects the healthy development of the cluster. With the proposal of China's "dual carbon" goal, the ecological development of clusters has become the new direction. The improvement of innovation ability is an important link to promote the green development of clusters [4]. The emergence of intelligent manufacturing, big data, artificial intelligence, and other emerging technologies have brought scientific and technological revolution and industrial transformation under the new normal. It has spawned a large number of new technologies, new models, and new forms of business. This state provides opportunities for the development of clustered ecosystems. In 2020, the Torch Center of the Ministry of Science and Technology of China released the "Opinions on Deepening the High-quality Development of Innovative Industrial Clusters." The ministry pointed out that the high-quality development of clusters focuses on the major strategic needs of the country and builds a modern regional economic system. Innovation can promote the evolution of the cluster ecosystem to a higher level and strengthen the correlation of scientific activities within the system. Innovative industrial cluster is a typical form of cluster ecosystem and plays an important radioactive effect on regional economic development. It can stimulate the innovation vitality and power of enterprises in the cluster and promote the conquest of key core 
technologies. Many related industries are radiated and trigger the development. This can realize the cluster from the low order chaos to the evolution of the higher-order order [5]. Therefore, the dynamic evolution of the cluster ecosystem is a transition process from a small cluster to a large cluster and from low quality to high quality. It is well known that the cluster ecosystem has the characteristics of mutualism, resource sharing, self-organization evolution, and cooperation in opening [6]. This enables the cluster ecosystem to form a geographical range of multiple industries to cooperate, a large number of organizations and members into a community of common destiny. Many industrial clusters are not born naturally but under the arrangement of the government system in China [7]. This makes institutional governance have a great influence on the evolution of the cluster ecosystem. Thus, the improvement of the quality and efficiency of the cluster ecosystem cannot be achieved by a single factor. How to solve the high-quality development of a cluster ecosystem has become an urgent problem.

In conclusion, the main innovations of this paper are as follows: (1) this paper uses the combination of origin method and pseudocode to sort out the synergy model of cluster ecosystem. (2) This study focuses on the collaborative development of innovation and institutional governance in the cluster ecosystem. Rather than an accumulation of subsystems, it is an in-depth excavation of the correlation degree of elements in each system through the sequence parameter variables. It aims to achieve high-quality development of the cluster ecosystem in the process of dynamic competition and cooperation.

\section{Literature Review and Theoretical Basis}

2.1. Cluster Ecosystem and Institutional Governance. Cluster ecosystem grants cluster a world-class competitiveness [8]. China's cluster development occurs more from policy incentives, financial support, and other institutional means of governance [9]. Several researchers have proved that system governance can improve cluster innovation performance [10]. Therefore, institutional governance has become the daily management activities of cluster ecosystem [11]. Innovation institutional governance was first proposed by Douglas North [12]. Institutional governance mainly involves control activities from the perspective of institutional innovation behavior to further stimulate and encourage the innovation atmosphere. Governance measures, regulations, procedures, and other institutional behaviors are adopted to regulate the innovation activities of the cluster ecosystem. Hence, they provide a standardized, scientific, and procedural development environment for a high level of cluster development [13]. Some scholars believe that the institutional governance of the cluster ecosystem has become the basis for supporting the sustainable development of organizational activities [14]. The governance of relationships within the cluster ecosystem can improve resilience and resist external risks [15]. Liu believes that the governance of the cluster ecosystem is closely related to the internationalization ability, which provides a direction for the exploration of national competitiveness [16]. From the perspective of ecological symbiosis, Yu and Sui discussed the realization of urban cluster ecological system under the management of symbiosis mechanism. It ensured the exchange of technology, knowledge, information, and other resources [17]. Some regions have regarded the cluster ecosystem as a model of industrial transformation and development [18].

Some scholars believe that the cluster ecosystem needs to take a professional governance. Nie et al. believe that the cluster ecosystem has endogenous power systems, such as capital, talents, technology, and other power resources support. Such systems are closely related to the professional governance of the cluster itself [19]. In terms of the institutional governance of the enterprise innovation cluster, Sun et al. carried out in-depth excavation [20] and divided the institutional governance into three layers of professional evolution structure namely. The layers include the genetic system governance [21], mediation system governance $[22,23]$, and variant system governance [24]. In terms of national governance, Zhang et al. believe that the reform of the professional industrial system and policy improvement are important forces to accelerate the development of cluster ecosystem [25]. Over the past many years, many cluster leaders have made decisions in a "one-size-fits-all" perspective with often results lower than expected. In that regard, Coletti et al. believe that institutional governance should be closely designed to increase the flexibility of leader decision-making [26]. Maracha et al. pointed out that a new innovative industrial cluster ecosystem of advanced form, especially the digitization of governance, drives the collapse of cluster heterogeneous structures [27].

2.2. Cluster Ecosystem and Innovation. The development of clusters requires the empowerment of innovative elements to promote their high-quality development [28]. The openness and sharing characteristics of the cluster ecosystem make the technical knowledge greatly transmitted internally and form a certain knowledge spillover effect [29]. However, such spillover is a "double-edged sword" for innovation. At present, many scholars have not conclusively established a clear relationship between knowledge spillover and innovation in clusters [30]. However, the dissemination of knowledge in clusters can certainly increase innovation benefits and improve the advancement of organizations in clusters [31]. The double-cycle development pattern provides huge market opportunities for clusters, attracts advanced elements from all over the world, produces the aggregation of innovative elements, and reduces transaction costs. Besides, it promotes the industry chain to get out of the low-end dilemma and promotes the formation of worldclass quality industrial cluster ecosystem [32]. The innovation and development of a cluster ecosystem are often accompanied by collaborative behavior in the process of cooperation [33]. Ying-Jing Chu et al. posit that such synergy can produce a spatial effect, which is conducive to the aggregation of innovation elements [34]. An organizational form with cross-industry and cross-region driving effects can be formed through the division of labor, cooperation, and collaborative innovation [35]. 
As a symbol of regional competitiveness, the cluster has several top innovation clusters that can promote regional development [36]. Germany was one of the first countries to attach importance to cluster development. Chen opines that Germany dares to break down barriers in close cooperation between industry, university, and research and build innovation clusters oriented at problem-solving and research [37]. Gao et al. pointed out that the close linkage between clusters and innovation not only promotes regional economic development but also forms cultural confidence. Such linkage is conducive to narrowing the regional development gap and promoting the generation of regional brands [38]. With the rise of "Internet + ", cross-border e-commerce has become a key point of regional economic development. Fang Zhou found that the high-quality development of crossborder e-commerce clusters of foreign trade enterprises requires a systematic investment of innovative resources to form a collaborative ecological environment [39]. Similarly, Zhou et al. alluded that China is entering an era of highquality development. Thus, regional development cannot be separated from systematic innovation of clusters at the level of the value chain, industrial chain, and knowledge chain [40]. Wei et al. started from the perspective of innovation chain evolution in university science parks. They explained the process of the evolution of regional innovation clusters into national innovation poles, which need systematic basic innovation support [41]. Wen et al. took the GuangdongHong Kong-Macao Greater Bay Area as an example to build world-class clusters. They highlighted that the synergy between cluster driving and systematic innovation development is the key to achieving world-class competitiveness [42].

The system of governance and innovation for cluster has a great effect on the high quality of the ecological system. A few scholars agree on the perspective of the relationship between innovation and institutional governance study of the cluster. Therefore, this article further explored the cluster innovation ecosystem under the innovation system and system management system of a collaborative relationship; the high-quality development of the cluster ecosystem provides a new direction.

\section{Deduction of a Collaborative Model of Cluster Ecosystem}

There are many ways to deduce the cooperative model of a cluster ecosystem. This paper is enlightened by the research of Xie et al. [43]. The code backtracking algorithm is selected to deduce the cluster cooperation model. And the deduction process is described by pseudocode. So this is helpful to understand the realization logic of the collaborative model of innovation system and institutional governance system in cluster ecosystem. The specific deduction process is as shown in Algorithm 1.

Code TraceBack method was used to trace the formula file and function declaration to reflect the real needs [44]. It can be seen from formula file tracing (pseudocode lines 1-60) that cluster system $T$ has the situation of synergy and accumulation state $\mathrm{T}$. We set up the conditional program to obtain the coexistence. The preprocessing module parses its files to increase the matching degree of system T. So the cumulative effect formula of the system can be obtained (pseudocode lines 22-35). The result output is pseudocode lines 32. Ergodicity exists in the traceability of the formula file and function declaration. The optimal static cooperation state is finally formed in pseudocode lines 37 . This formal parameter is used in the line of code in the function body when the function is deformed. When tracing the function to the source, it will be unable to match with the code assembly instruction set, which requires instruction exit and redetermination. pseudocode lines 32 and 37 show that the cluster system can be regarded as several subsystems (pseudocode lines 22-40). Further, the existence of synergistic effect is greater than nonsynergistic effect, and there is an optimal solution for such synergy.

This paper expanded the dynamic evolution, which is based on the traceability of static formula function. The order parameter functions are applied to static libraries to generate variable formula instructions with upper and lower bounds, while the dynamic system $T_{\mathrm{r}}$ is judged. If the collaborative development within the cluster system reaches a certain state, function tracing is expected to become an instruction sequence rule. System $T_{\mathrm{r}}$ can be made to reach a stable state in pseudocode lines 44 (pseudocode lines 41-47). Then, there is a certain range of order parameter $\lambda_{\text {ri }}$. The more orderly and stable the system, the higher the weight in pseudocode lines 50 (pseudocode lines 48-53). At any time node $t \in\left[t_{0}, t_{1}\right]$, the order parameters of each subsystem are adjusted to store the function names with high matching correlation. This makes the dynamic composite system composed of formula file traceability and function traceability achieve stable coordination on the whole. By identifying each SourceFunc element, the program traces and compares the program source, which generate the corresponding dynamic composite system in pseudocode lines 55 (pseudocode lines 54-59). The degree of synergy presented is directly proportional to the degree of correlation between function values (pseudocode lines 48-60).

\section{Model Index Construction and Data Collection}

4.1. Variable Selection. This paper draws on the existing research results. The $\mathrm{R} \& \mathrm{D}$ expenditure and number of $\mathrm{R} \& \mathrm{D}$ personnel are regarded as explanatory variables in innovation system $[45,46]$. According to the existing experience, $70 \%$ of the profits of innovative enterprises and high and new technology clusters come from technological innovation [47]. As a result, innovation income is another explanatory variable of innovation system [48]. The number of high-tech enterprises identified [20], Government S\&T support funds [49], and system number [50] are taken as indicator variables in the innovation institutional governance system. In this way, the factors in the formula of the synergistic complex system can be constituted. 
(1) Input: Source_code_path in Cluster ecosystem T.

(2) $\mathrm{T}$ : the relational function of the element

(3) $\mathrm{E}^{\mathrm{g}}(\mathrm{T})$ : compound relationship is formed in innovation cluster

(4) $T_{\mathrm{r}}$ : subsystem $r$ in innovation System $\mathrm{T}$

(5) $\mathrm{F}^{\mathrm{n}}$ : a collection of synergies

(6) $\mathrm{F}^{0}$ : the optimal solution of innovate synergy

(7) g: a system formed by collaboration

(8) $\mathrm{g}^{0}$ : form the optimal state of the new system

(9) Opt: the optimal solution produced by $\mathrm{E}^{\mathrm{g}}(\mathrm{T})$ collaboration

(10) $\lambda_{\mathrm{r}}$ : set of order parameters in innovation system, $\lambda_{\mathrm{r}}=\left(\lambda_{\mathrm{r} 1}, \lambda_{\mathrm{r} 2}, \ldots \lambda_{r n}\right)$

(11) $\lambda_{\text {ri: }}$ order parameter stability value

(12) $\delta$ : the upper bound of the order parameter $\lambda_{\mathrm{ri}}$ in System $T$ steady state

(13) $\eta$ : the lower limit of the order parameter $\lambda_{\text {ri }}$ in System $T$ steady state

(14) $\mu_{\mathrm{r}}\left(\lambda_{\mathrm{ri}}\right)$ : order parameter degree of subsystem $T_{\mathrm{r}}$

(15) $\mu_{\mathrm{r}}\left(\lambda_{\mathrm{ri}}\right)$ : order degree of complex innovation system

(16) $W_{\mathrm{i}}$ : weight

(17) $\mu_{\mathrm{r}}\left(\lambda_{\mathrm{ri}}\right)$ : the order degree of complex system at time $t_{0}$

(19) $\mu_{\mathrm{r}}\left(\lambda_{\mathrm{ri}}\right)$ : the order degree of complex system at time $t_{1}$

(20) $\mathrm{U}_{\mathrm{d}}(t)$ : the overall collaborative stability of the innovation cluster composite system

(21) Output: Result Of Formula File Name, Result of FuncName.

(22) Source Code Set, Source Formula File Name set $\leftarrow$ read Formula files from Source_code_path's cluster system T

(23) Add FuncNames into Source FuncName Set

(24) Def compare Sets (Source Formula File Set, handle Func)

(25) Result Of Compare $\leftarrow \varnothing$

(26) For (int $r=$ begin, $r \leq n, r++$ ) do

(27) $\mathrm{T} \leftarrow$ handle Func $\left(f\left(T_{1}, T_{2}, \ldots, T_{r}, \ldots T_{n}\right)\right)$

(29) If cooperative Work $\& \&$ accumulative effect $==$ true

(30) Remove $T$ from Source Set

(31) Add $T$ match mark into result of compare

(32) Then print $\left(E^{g}(T)=E\left\{F\left[f\left(T_{1}, T_{2}, \ldots T_{n}\right)\right]\right\}=E\left[g\left(T_{1}, T_{2}, \ldots T_{n}\right)\right]>\sum_{r=1}^{n} E^{f}\left(T_{r}\right)\right)$

(33) //There are synergies between subsystems, which can form a cumulative effect.

(34) Else no match mark into result of compare

(35) End

(36) If $\left(\exists \mathrm{F}^{0} \in \mathrm{F}^{\mathrm{n}} \& \& g=g^{0}=\mathrm{F}^{0} \mathrm{f}\right)$ then

(37) $\quad \operatorname{optE}^{g}(T)=E\left\{F^{0}\left[f\left(T_{1}, T_{2}, \ldots T_{n}\right)\right]\right\}=E\left[g^{0}\left(T_{1}, T_{2}, \ldots T_{n}\right)\right]$

(38) Print (opt $\mathrm{E}^{\mathrm{g}}(\mathrm{T})$ is synergy and static by $T_{\mathrm{r}}$ )

(39) Else no match mark into result of compare

(40) End

(41) If $\left(T_{\mathrm{r}}\right.$ evolves stability\&\& $\lambda_{\mathrm{ri}} \in\left[\delta_{\mathrm{ri}}, \eta_{\mathrm{ri}}\right]==$ true $)$

(42) //In the process of subsystem evolution, there are order parameters with upper and lower limits, which make it develop stably.

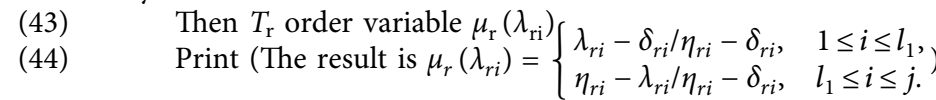

(45) //It forms the degree of order of the stable evolution of the subsystem.

(46) Else no match mark into result of compare

(47) End

(48) If $\mu_{\mathrm{r}}\left(\lambda_{\mathrm{ri}}\right) \in[0,1] \& \& w e i g h t\left(w_{i}>=0 \& \& \sum_{i=1}^{j} w_{i}=1\right)==$ true then

(49) //When the subsystem is stable and orderly, the weight is combined.

(50) $\quad$ Print $\left(\mu_{r}\left(\lambda_{r}\right)=\sum_{i=1}^{j} W_{i} \mu_{i}\left(\lambda_{r i}\right)\right)$

(51) //This forms the stable and orderly degree of complex system evolution.

(52) Else no match mark into result of compare

(53) End

If $\left(\mathrm{t} \in\left[t_{0}, t_{1}\right] \& \& \mu_{\mathrm{r}}\left(\lambda_{\mathrm{r}}\right) \in\left[\mu_{r}{ }^{0}\left(\lambda_{r}\right), \mu_{r}{ }^{1}\left(\lambda_{r}\right)\right]==\right.$ true $)$

(55) Print $U_{d}(t)=\sum_{r}^{n} W_{i}\left[\left|\mu_{r}{ }^{1}\left(\lambda_{r}\right)-\mu_{r}{ }^{0}\left(\lambda_{r}\right)\right|\right] \times \min _{r}\left[\mu_{r}{ }^{1}\left(\lambda_{r}\right)-\mu_{r}{ }^{0}\left(\lambda_{r}\right)\right] /\left|\min _{r}\left[\mu_{r}{ }^{1}\left(\lambda_{r}\right)-\mu_{r}^{0}\left(\lambda_{r}\right)\right]\right|$.

(56) Get Source Func $\left(U_{\mathrm{d}}(\mathrm{t})\right)$

(57) End

(59) End for

(60) Result Of Formula File Name $\leftarrow$ Compare Sets (clone Source FuncNameSet) 
4.2. Experimental Data Collection. Three biomedicine clusters represent the level of development in north, central, and south China, which were used in this study. They were Tonghua, Zhangjiang, and Nanchang biomedicine clusters. The data were selected from official channels such as China Torch Statistical Yearbook, Local Statistical Yearbook, and Government Statistical Bulletin. It was found that the 2012 yearbook is not the latest edition, and problems such as statistical data faults and inconsistent standards exist. Therefore, in this study, the time range for data search is 2014-2020. Since the yearbook and other statistical data are based on the previous period, the data selected in this paper is from 2013 to 2019. Meanwhile, in terms of institutional governance, the official websites of local governments we searched are from directly managed departments. The provincial governments of the three biological clusters and the counted number of relevant systems were released each year. The specific data are shown in Tables 1-3.
4.3. Synergy and Correlation Model. According to pseudocode lines 55, the synergy between the innovation system and institutional governance system in the cluster ecosystem means that each element in the two subsystems has a close correlation with the evolution of time. The higher the correlation, the higher the degree of synergy between subsystems in the cluster. Therefore, this study measured the correlation degree between systematic innovation and innovation institutional governance system to explore the collaborative quality further. Correlation degree was achieved through Pearson correlation and correlation ratio, providing ideas for promoting the development of high-tech innovation clusters. This paper refers to the results of $\mathrm{Yu}-$ Shao Chen et al. research [51], and the specific Pearson correlation model is shown in formula (1). Among them, the correlation coefficient is represented by $\gamma$; the greater the absolute value of $\gamma$, the stronger the correlation. The Pearson correlation coefficient model was constructed as follows:

$$
\gamma=\frac{\sum_{i}^{n}\left(x_{i}-\bar{x}\right)\left(y_{i}-\bar{y}\right)}{\sqrt{\sum_{i}^{n}\left(x_{i}-\bar{x}\right) \sum_{i}^{n}\left(y_{i}-\bar{y}\right)}}=\frac{n \sum_{i=1}^{n} x_{i} y_{i}-\sum_{i=1}^{n} x_{i} \sum_{i=1}^{n} y_{i}}{\sqrt{n \sum_{i=1}^{n} x_{i}^{2}-\left(\sum_{i=1}^{n} x_{i}\right)^{2}} \sqrt{n \sum_{i=1}^{n} y_{i}-\left(\sum_{i=1}^{n} y_{i}\right)^{2}}}
$$

$\gamma$ indicates the degree of correlation between the innovation system and the innovation institutional governance system. $x_{i}$ represents the set of all explanatory variables in the innovation system. The $y_{\mathrm{i}}$ represents the set of all explanatory variables in the innovation institutional governance system. The magnitude of $\gamma$ is between $[-1,1]$. If $1 \geq \gamma>0$, it shows a positive correlation. If $-1 \leq r<0$, this indicates that the two variables are negatively correlated. If $\gamma=0$, it means irrelevant.

\section{Simulation Experiment and Discussion}

5.1. Correlation Simulation. In this study, pseudocode lines 32 was combined and correlation simulation carried out with empirical data. The data in Tables 1-3 were programmed with Matlab 2014a. Based on the phenomena in Figure 1, the biological cluster innovation system and innovation institutional governance system in Zhangjiang and Nanchang are relatively close to each other. Besides, the correlation between innovation system and innovation system governance system of Tonghua biomedical cluster is weak. The correlation development of the three biomedical clusters showed a fluctuating state, indicating instability in the correlation development. The positive correlation was relatively high in Nanchang and Zhangjiang biomedical high-tech clusters. Tonghua biomedical cluster was the lowest.

Zhangjiang and Nanchang biomedical clusters had the lowest positive correlation in 2015. The correlation of the Zhang jiang reached its maximum in 2016 while Nanchang had the highest correlation in 2013. In the 7 years of Zhangjiang and Nanchang biomedical clusters, the correlation between the innovation system and the innovation system governance system fluctuated around 0.8 . However, the correlation of the Tonghua biomedical cluster fluctuates around -0.2 with a large fluctuation range. Because of the fluctuation of correlation, the dynamic coordination of the innovation system and innovation institutional governance system of the three biomedical clusters has not reached the optimal level. Therefore, this paper focused on how to promote the innovation system and innovation institutional governance system to achieve the optimal coordination state. Greater attention was given to the use of adjusting order variables to achieve the optimal state for all parties in Figure 1.

5.2. Adding the Test of Order Parameters. According to pseudocode lines 32, a regulating order parameter was added between the variables of innovation institutional governance system and innovation system. Its values ranged from 0 to 1 . Matlab2014a was used to adjust the order parameter. After the actual adjustment of the order parameter test, the optimal coordination state in Figure 2 was obtained. The trend of dynamic coordination was Zhangjiang $>$ Nanchang $>$ Tonghua in 7 years. The correlation degree of the three was more compact, hence indicating an upward trend. After adjustment of order variables, the following mathematical expressions could be obtained in this study: [TongHua, ZhangJiang, NanChang] $]^{\mathrm{T}}=$ $\left[\begin{array}{cccccc}1.3 & -1.2 & 1 & 1.3 & 1.2 & 1.66 \\ 0.01 & 0.03 & 0.016 & 0.036 & 0.21 & 0.24 \\ 0.95 & 1 & 0.9 & 0.95 & 0.98 & 1\end{array}\right]$.

Matrix expression was the order variable intensity to be adjusted for the three biomedical clusters. According to pseudocode lines 47, adjusting the weight of order parameters could promote stability. Tonghua cluster achieved orderly and stably development, which needed to adjust bigger weight value. The order parameter weight adjusted by 
TABle 1: Tonghua biomedical high-tech cluster.

\begin{tabular}{|c|c|c|c|c|c|c|}
\hline \multirow[b]{2}{*}{ Year } & \multicolumn{3}{|c|}{ Innovation system } & \multicolumn{3}{|c|}{ Institutional governance system } \\
\hline & $\begin{array}{l}\text { R\&D expenditure } \\
(100 \text { million yuan })\end{array}$ & $\begin{array}{l}\text { Innovation profit } \\
(100 \text { million yuan })\end{array}$ & $\begin{array}{c}\text { Number of R\&D } \\
\text { personnel }\end{array}$ & $\begin{array}{l}\text { Number of high-tech } \\
\text { enterprises identified }\end{array}$ & $\begin{array}{l}\text { Government S\&T support } \\
\text { funds ( } 100 \text { million yuan })\end{array}$ & $\begin{array}{l}\text { System } \\
\text { number }\end{array}$ \\
\hline 2013 & 0.99 & 25.34 & 1370 & 9 & 1.095 & 7 \\
\hline 2014 & 1.31 & 36.82 & 1532 & 9 & 0.543 & 8 \\
\hline 2015 & 2.4 & 44.1 & 1700 & 10 & 0.5765 & 9 \\
\hline 2016 & 2.5 & 55.13 & 1121 & 11 & 0.692 & 12 \\
\hline 2017 & 1.7 & 18.95 & 963 & 12 & 0.6449 & 8 \\
\hline 2018 & 1.24 & 17.67 & 1482 & 13 & 0.65 & 14 \\
\hline 2019 & 1.43 & 14.43 & 1483 & 19 & 9.9 & 10 \\
\hline
\end{tabular}

TABLe 2: Zhangjiang biomedical high-tech cluster.

\begin{tabular}{|c|c|c|c|c|c|c|}
\hline \multirow[b]{2}{*}{ Year } & \multicolumn{3}{|c|}{ Innovation system } & \multicolumn{3}{|c|}{ Institutional governance system } \\
\hline & $\begin{array}{l}\text { R\&D expenditure } \\
(100 \text { million yuan })\end{array}$ & $\begin{array}{l}\text { Innovation profit } \\
(100 \text { million yuan })\end{array}$ & $\begin{array}{l}\text { Number of R\&D } \\
\text { personnel }\end{array}$ & $\begin{array}{l}\text { Number of high-tech } \\
\text { enterprises identified }\end{array}$ & $\begin{array}{l}\text { Government S\&T support } \\
\text { funds ( } 100 \text { million yuan })\end{array}$ & $\begin{array}{l}\text { System } \\
\text { number }\end{array}$ \\
\hline 2013 & 264.81 & 728.93 & 84171 & 1024 & 3.32 & 4 \\
\hline 2014 & 278.41 & 996.75 & 98001 & 2065 & 3.33 & 2 \\
\hline 2015 & 434 & 1333.99 & 123679 & 2576 & 12 & 3 \\
\hline 2016 & 470.06 & 1609.03 & 132040 & 2838 & 26.36 & 4 \\
\hline 2017 & 471.76 & 1883.27 & 142970 & 3675 & 26.58 & 8 \\
\hline 2018 & 481.47 & 2041.97 & 135210 & 4314 & 13.5 & 22 \\
\hline 2019 & 478.71 & 2186.41 & 117586 & 6514 & 14.62 & 16 \\
\hline
\end{tabular}

Table 3: Nanchang biomedical high-tech cluster.

\begin{tabular}{|c|c|c|c|c|c|c|}
\hline \multirow[b]{2}{*}{ Year } & \multicolumn{3}{|c|}{ Innovation system } & \multicolumn{3}{|c|}{ Institutional governance system } \\
\hline & $\begin{array}{l}\text { R\&D expenditure } \\
(100 \text { million yuan })\end{array}$ & $\begin{array}{l}\text { Innovation profit } \\
(100 \text { million yuan })\end{array}$ & $\begin{array}{c}\text { Number of R\&D } \\
\text { personnel }\end{array}$ & $\begin{array}{l}\text { Number of high-tech } \\
\text { enterprises identified }\end{array}$ & $\begin{array}{l}\text { Government S\&T support } \\
\text { funds ( } 100 \text { million yuan })\end{array}$ & $\begin{array}{l}\text { System } \\
\text { number }\end{array}$ \\
\hline 2013 & 29.36 & 49.2 & 15540 & 95 & 1.5 & 1 \\
\hline 2014 & 29.79 & 57.38 & 14878 & 122 & 3.1 & 5 \\
\hline 2015 & 35.93 & 71.42 & 12503 & 136 & 2.4 & 4 \\
\hline 2016 & 47.62 & 120.58 & 16903 & 160 & 2.86 & 4 \\
\hline 2017 & 58.54 & 127.28 & 20635 & 202 & 4.5 & 8 \\
\hline 2018 & 78.78 & 144.12 & 28587 & 307 & 5 & 6 \\
\hline 2019 & 79.4 & 152.15 & 27487 & 420 & 4 & 8 \\
\hline
\end{tabular}

Nanchang ranked second, while Zhangjiang needed the least weight value of order parameter. After adjustment, the ranking of cluster development trends was also Zhangjiang $>$ Nanchang $>$ Tonghua. In Figure 2, the positive correlation between Shanghai and Nanchang was between $(0.3,0.5]$, which belonged to a moderate correlation. This scope indicated that the degree of coordination between Zhangjiang and Nanchang had a certain foundation. The simulation results in Figure 2 showed that coordination states were close to current situation of development of Chinese regional economy. Therefore, the optimal development of innovation and governance coordination lays a foundation for the green development of biomedical clusters, which has far-reaching practical significance.

5.3. Future Prediction and Discussion. The synod order parameters set in this study play a role in promoting the development of the current three biomedical clusters. It can be known from pseudocode lines 50 that the correlation of the three biomedical clusters will continue to play a role in the next few years. It is predicted that the collaborative development of the innovation system and innovation institutional governance system can continue to maintain the optimal effect after two years. The details are shown in Figure 3. This effect is very significant for the late catch-up of the Tonghua biomedical cluster. In the ninth year, Tonghua and Nanchang biomedical cluster can be realized in the same echelon. Therefore, the innovation system is set as variable $\mathrm{A}$ in this paper. Then the three variables are $A_{1}, A_{2}$, and $A_{3}$, respectively, in the system. Similarly, innovation agency governance system is set as variable $B$. Then the three variables are $B_{1}, B_{2}$, and $B_{3}$, respectively in the system. Thus the correlation between subsystem $A$ and subsystem $B$ can be expressed as the correlation between each factor. We set $\mathrm{A}=$ $\left\{A_{1}, A_{2}, A_{3}\right\}=\{R \& D$ expenditure, Innovation profit, Number of $R \& D$ personnel $\}$. And $B=\left\{B_{1}, B_{2}, B_{3}\right\}=\{$ Number of high-tech enterprises identified, Government $S \& T$ support funds, System number $\}$. This is expressed as $\left[A_{1} B_{1}, A_{1} B_{2}\right.$, $\left.A_{1} B_{3}, A_{2} B_{1}, A_{2} B_{2}, A_{2} B_{3}, A_{3} B_{1}, A_{3} B_{2}, A_{3} B_{3}\right]$. The specific correlation values of each element of the three biomedical clusters were obtained. According to formula (1), the 


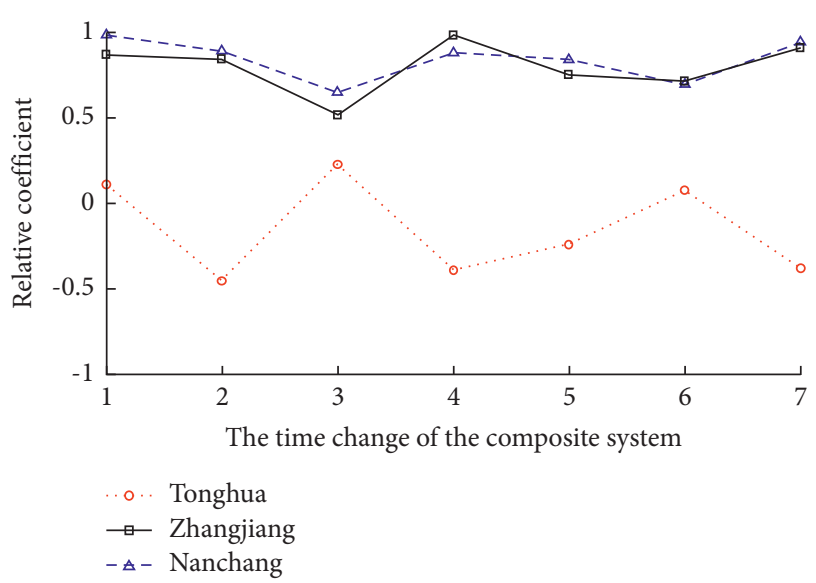

Figure 1: Comparison of the degree of synergy among three biomedical clusters.

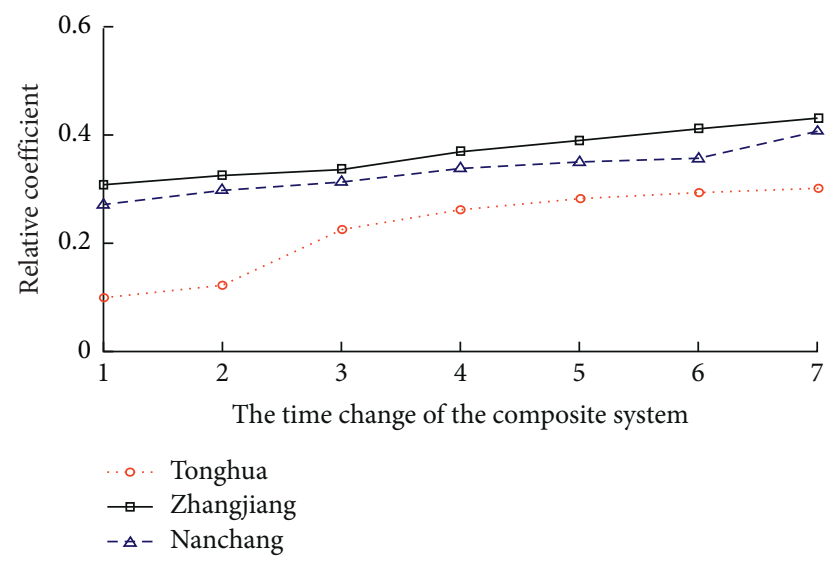

FIGURE 2: Synergistic effect of order parameter improvement.

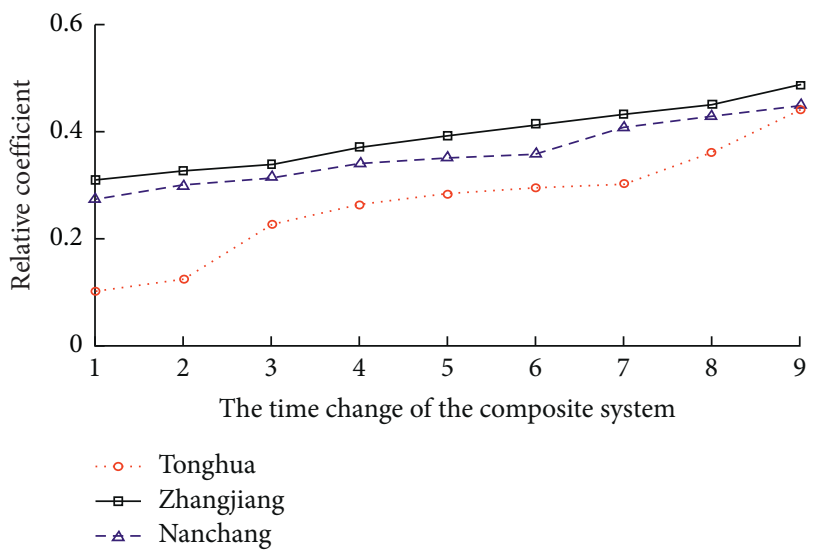

FIgURE 3: The prediction of synergy trends.

correlation of all elements in Tonghua cluster is $[0.5,0.24,2$, $1.3,0.55,2.6,1.5,0.7,3.9]$. The correlation of all elements in Zhangjiang cluster is $[0.4,0.55,0.59,0.48,0.66,0.72,0.56$, $0.76,0.85]$. The correlation of all elements in Nanchang cluster is $[0.4,0.35,0.42,0.5,0.41,0.48,0.6,0.5,0.6] . \mathrm{A}_{3} \mathrm{~B}_{3}$ was the best element correlation in Zhangjiang biomedical cluster. $A_{3} B_{1}$ and $A_{3} B_{3}$ was the best element correlation in
Nanchang biomedical cluster. However, there are several cases in which the correlation coefficient of the Tonghua biomedical cluster exceeds 1 . This does not conform to the value range of correlation, so the optimal coordination state of the Tonghua biomedical cluster cannot be implemented. Therefore, if Tonghua biomedical cluster wants to change the current situation of not achieving optimal synergy, it needs to change the existing innovation and development structure to change the revenue data.

\section{Conclusion and Enlightenment}

The level of regional economic development in China is closely related to the quality of the cluster ecosystem. Due to the differences in institutional governance level and innovation capability, the collaborative state of the cluster ecosystem in different regions has significant heterogeneity. As a typical state in the evolution of the cluster ecosystem, the innovation-oriented industrial cluster has become an important driving force of regional innovation. It is led by industry and based on cooperation with universities and research institutes, which provides conditions for the highquality development of the cluster ecosystem.

In the construction of synergistic relationship, innovation and institutional governance influence and interact with each other. Thus, it plays a positive role in the sustainable development of the cluster ecosystem. Systematic innovation integrates various innovation subjects and elements in the cluster and provides a platform for innovative talents of high-tech enterprises in the cluster ecosystem. In addition, the characteristics of the cluster ecosystem, such as selforganization and openness, make it inseparable from the support of institutional governance, guide the cluster to avoid some risk factors, and realize the improvement of innovation efficiency.

The stronger the correlation between innovation system and institutional governance system, the higher the collaborative quality of cluster ecosystem. According to the development data of the three biomedicine clusters, Zhangjiang ranks the highest in synergy quality, Nanchang the second, and Tonghua the last. At the same time, this paper found that Zhangjiang and Nanchang can achieve the best coordination state, but Tonghua cannot. Further analysis shows that there is the highest correlation between the number of R\&D personnel and the number of institutions in Zhangjiang. In that regard, Zhangjiang attaches great importance to talent attraction and realizes the coordination between institutional governance and R\&D talent attraction within the cluster. Nanchang biomedical cluster attaches importance to the development of high-tech enterprises innovation elements of the "reservoir" function. The system has also issued a considerable level of governance and formed a highly related development environment. Tonghua biomedicine cannot achieve the state of coordinated development. If Tonghua wants to change this state, it needs to change the current institutional governance system and further improve the innovation benefits of the cluster ecosystem. Therefore, the correlation between the innovation system and institutional governance system has a direct 
impact on the synergy level of biomedical clusters. Thus, it provides a certain reference for promoting the high-quality development of the cluster ecosystem.

\section{Data Availability}

The Government Support Fund data used to support the findings of this study have been deposited in the National Bureau of Statistics of China repository (http://www. stats.gov.cn/tjsj/ndsj/). The Identification of High-Tech Enterprises data used to support the findings of this study were supplied by Torch High-Tech Industry Development Center, Ministry of Science and Technology of China, under license and so cannot be made freely available. Requests for access to these data should be made to http:// www.yearbookchina.com, https://www.yearbookchina. com/navibooklist-n3020013200-1.html. The Innovation Profit data used to support the findings of this study were supplied by Torch High-Tech Industry Development Center, Ministry of Science and Technology of China, under license and so cannot be made freely available. Requests for access to these data should be made to http:// www.yearbookchina.com, https://www.yearbookchina. com/navibooklist-n3020013200-1.html. The Patent for Invention data used to support the findings of this study were supplied by Torch High-Tech Industry Development Center, Ministry of Science and Technology of China, under license and so cannot be made freely available. Requests for access to these data should be made to http:// www.yearbookchina.com, https://www.yearbookchina. com/navibooklist-n3020013200-1.html.

\section{Conflicts of Interest}

The authors declare that they have no conflicts of interest.

\section{Acknowledgments}

This article was funded by the National Natural Science Foundation of China "Study on the identification and regulation of strategic change process under the coordination of multiple order parameters" (Grant nos. 71402104 and 7140210). This work was supported in part by Shenyang Science Project "Research on the system and mechanism of Shenyang industrial technology innovation research institute" (Grant no. 17-232-5-08) and Shenyang Industry Innovation Resource Report Preparation (Grant no. 2019-043-027).

\section{References}

[1] H. Q. Lai, "On the ecology and sustainable development of industrial clusters," Contemporary Economy, no. 8, pp. 58-61, 2020.

[2] E. H. Zhang, "Exploration on the relationship between industrial cluster and regional economic development-- take Nanjing integrated circuit industrial cluster and regional economic development as an example," Economic Research Guide, no. 23, pp. 30-32, 2021.
[3] L. X. Yang, "China's industrial innovation ecosystem optimization and industrial overcapacity prevention," Reform and Strategy, vol. 37, no. 6, pp. 26-35, 2021.

[4] X. B. Feng and H. Liu, "The impact of cluster enterprise crossborder search on green innovation studies the regulatory role of--management interpretation," Research and Development Management, vol. 33, no. 4, pp. 28-40, 2021.

[5] N. Guo and Z. P. Guo, "Research on innovative industrial Cluster and regional financial Development-_take Shenzhen's next generation of Internet innovative industrial cluster as an example," Regional Finance Research, no. 6, pp. 41-51, 2019.

[6] M. F. Li, "Composition, characteristics and evolution of industrial cluster brand ecosystem," Enterprise Economy, vol. 36, no. 3, pp. 23-28, 2017.

[7] C. Huang and H. B. Long, "Government auxiliary system work, system logic and cluster upgrading - - case study based on the cluster evolution in Yuyao and Anji," Manage the world, no. 6, pp. 148-166, 2016.

[8] P. Zhang and Z. Q. Zhao, "The EU model for fostering worldclass competitiveness clusters and its implications," China Soft Science, no. 12, pp. 72-80, 2019.

[9] M. S. Sun, "Local government promoting industrial cluster-- take jiangxi province as an example," Journal of China Management Information Technology, vol. 24, no. 6, pp. 209-210, 2021.

[10] J. L. Ye, "The knowledge spillover, governance effect and industrial cluster innovation performance of leading enterprises," Journal of Governance Research, vol. 37, no. 02, pp. 110-117, 2021.

[11] F. Q. Wu and R. X. Bai, "Ecological analysis of innovative cluster evolution," Journal of Practice and knowledge of mathematics, vol. 50, no. 01, pp. 321-325, 2020.

[12] D. C. North, "Economic performance through time," The American Economic Review, vol. 84, pp. 359-368, 1994.

[13] P. F. Cheng, X. D. Guan, and C. G. Su, "Research on the influence of science and technology finance on cultivating a world-class manufacturing cluster in China--take hunan rail transit industry cluster as an example," Hunan Social Sciences, no. 05, pp. 77-84, 2021.

[14] K. Liu and Y. R. Qiao, "Evolutionary mechanism of industrial cluster innovation ecosystems," Journal of Business Economics Research, no. 10, pp. 180-184, 2020.

[15] G. J. Yu and C. F. He, "Industrial cluster resilience: technological innovation, relationship governance and market diversification," Journal of Geographic studies, no. 06, pp. 113-126, 2020.

[16] T. M. Liu, "Study on the international governance ability of the industrial cluster," Journal of Hunan Institute of Finance and Economics, vol. 35, no. 02, pp. 85-93, 2019.

[17] X. Z. Yu and Y. H. Sui, "Research on the symbiotic mechanism of industrial cluster ecosystem based on urban innovation," Journal of Technology and Innovation Management, vol. 40, no. 01, pp. 19-24, 2019.

[18] X. L. Tan, "Innovation ecosystem construction of manufacturing industry cluster in the Guangdong-Hong Kong-Macao greater Bay Area," Journal of Modern Marketing, no. 01, p. 232, 2019.

[19] J. S. Nie, C. Y. Liu, and T. Nie, "The endogenous growth of professional clusters and their governance specialization," Journal of Modern education management, no. 09, pp. 111$118,2021$.

[20] J. Sun, H. Zou, and J. Xu, “Analysis of the behavior evolution of enterprise progressive innovation network and government 
system," Journal of China Science and Technology Forum, no. 03, pp. 43-52, 2021.

[21] J. W. Li and Y. Yuan, "The replication and Simulation of organizational practices--A Field theory of Innovation," Journal of Beijing University of Technology, vol. 18, no. 03, pp. 38-44, 2018.

[22] D. C. North, Institutions, Institutional Change and Economic Performance, pp. 31-80, Cambridge University Press, New York, NY, USA, 1990.

[23] Y. H. Wang, Y. Q. Song, and M. Nie, "Adaptive characteristics and principle analysis of institutional reform in China," Journal of Social Science, Tianjin, no. 01, pp. 108-115, 2017.

[24] S. G. Zheng, "Institutional variation in the reform of science and technology system," Digest of Management Science, vol. 7, pp. 38-39, 1998.

[25] Y. P. Zhang and Y. Sun, "Policy mirror of industrial cluster: thinking based on national governance," Journal of Economic Forum, no. 04, pp. 64-73, 2021.

[26] M. Coletti, P. Landoni, and F. Frattini, "Which clusters characteristics influence their governance an appraisal of international cases," International Journal of Competitiveness, vol. 2, no. 1, pp. 42-61, 2021.

[27] B. S. MarachaV, "Transforming relationship between neopatrimonial state and business for the sustainable development: cluster Governance model," E3S Web of ConferencesVolume, no. 108, pp. 07-029, 2020.

[28] S. Yao, M. L. Ji, and Y. J. Lai, "Research on time and space on efficiency of innovative industrial cluster in the yangtze river economic belt," Journal of Statistics and decision-making, vol. 37, no. 16, pp. 98-101, 2021.

[29] L. Wang, "Important views of industrial cluster knowledge innovation," Journal of Technical Economy, vol. 39, no. 10, pp. 145-154, 2020.

[30] J. P. Yang, N. Hou, and L. Wang, "Knowledge overflow, knowledge potential energy, and cluster innovation performance within the cluster," Journal of Management Engineering Journal, vol. 30, no. 03, pp. 27-35, 2016.

[31] P. Lu and K. X. Ma, "Research on income distribution mechanism of cluster supply chain based on ative risk sharing," Journal of Operations Funding and Management, vol. 29, no. 09, pp. 115-123, 2020.

[32] Y. Feng, "Enterprise cluster cost management based on the "double-cycle" pattern," Journal of Financial and Accounting Monthly, no. 23, pp. 36-43, 2020.

[33] Y. C. Ma and W. Guo, "Evolutionary game analysis of enterprise-embedded cluster collaborative innovation network behavior," Journal of Technology and Innovation Management, vol. 42, no. 05, pp. 489-497, 2021.

[34] Y. J. Chu and Y. M. Zhou, "Industrial cluster collaborative innovation, spatial association and innovation agglomeration," Journal of Statistics and Decision Making, vol. 36, no. 23, pp. 107-111, 2020.

[35] Y. H. Ma, H. J. Liu, and Q. Liu, "Differential game study of industrial cluster collaborative creative knowledge sharing strategy," Journal of Operations Funding and Management, vol. 29, no. 09, pp. 82-88, 2020.

[36] Q. Chen, H. Wang, and Si Guo, "Research and enlightenment on the government division of labor and cooperation in the German innovation cluster initiative," Journal of German Studies, vol. 35, no. 02, pp. 4-18, 2020.

[37] Y. Chen, "The heidelberg model and enlightenment of regional innovation cluster development in Germany," Journal of Chinese University Technology, no. 04, pp. 58-61, 2021.

[38] H. C. Gao and F. Y. Ji, "Regional breakthrough, cluster aggregation and institutional innovation - - high-quality development of cultural industry during the 14th Five-Year Plan period," Journal of Administrative Management Reform, vol. 2021, no. 02, pp. 16-27.

[39] F. Zhou, "Based on cross-border E-commerce cluster - takes suzhou as an example," Journal of Business \& Economics Research, no. 23, pp. 115-118, 2019.

[40] Y. M. Zhou and Q. K. Sang, "Research on high-quality innovation mode and route of industrial cluster collaborative in national self-created zone," Journal of Scientific and technological progress and countermeasures, vol. 37, no. 02 , pp. 5965, 2020.

[41] P. Wei and X. Y. Gao, "Research on the development model of China university science and technology park-_based on the survey of university science and technology parks in beijing, Shanghai, wuhan and other places and the comparative analysis between China and abroad," Journal of Science and Technology Management Research, vol. 39, no. 21, pp. 20-25, 2019.

[42] Y. Wen, S. F. Cai, and J. L. Xiao, "Opportunities and challenges for building innovative industrial clusters in the Guangdong-Hong Kong-Macao Greater Bay Area," Journal of Macroeconomic Management, no. 07, pp. 64-72, 2019.

[43] W. G. Xie, Q. LI, and C. Y. MA, "Traceability method of EMBEDDED Processor P2020 machine Code program to C language source program," Acta Aeronautica Sinica, vol. 42, no. 09 , pp. $514-529,2021$.

[44] Y. W. Tong and J. F. Liu, "Research on source-to-object code traceability analysis of Civil Aircraft CLASS A airborne software Project," Science and Technology Vision, no. 20, pp. 3-4, 2016

[45] T. Qi, L. H. Chen, and H. Q. Wang, "Empirical analysis on the relationship between government R\&D subsidy and innovation performance of new energy vehicle enterprises: based on the mediating effect of R\&D expenditure and technology level," Journal of predicting, vol. 39, no. 05, pp. 16-22, 2020.

[46] J. J. Zgao, "Application of ARIMA model in forecasting R\&D number in Chongqing," Journal of Agricultural consultant, no. 10 , p. $217,2019$.

[47] S. S. Cai, G. J. Ou, L. L. Zhao, and Y. N. Bian, "Research on ecological quality evaluation of innovation system in hightech development zone -- taking hubei high-tech zone as an example," Journal of Scientific research management, vol. 39, no. S1, pp. 87-94, 2018.

[48] B. Huang, "Ecological relationship, innovation returns and innovation cluster evolution," Enterprise Economics, no. 6, pp. 59-64, 2016.

[49] G. H. Xie, Y. Hao, and S. F. Jin, "Research on the influence of venture capital on the Effectiveness of innovation Incentive of government subsidy," Journal of Management, vol. 15, no. 09, pp. 1337-1346, 2018.

[50] Z. Y. Pei, A. X. Hu, J. J. Yan, and Y. Wang, "Research on innovation policy of pharmaceutical industry in Shanxi Province based on synergy degree," China Pharmacy, vol. 30, no. 16, pp. 2176-2218, 2019.

[51] Y. S. Chen, Z. J. Tang, and Y. Luo, "Research on stock price prediction based on Pearson optimization combined with XGBoost algorithm," Journal of Information Technology, no. 9, pp. 84-89, 2018. 